\title{
Is Nodular Gastritis a Precancerous Condition?
}

\author{
Eda Demir Onal
}

Received: 21 February 2012/ Accepted: 30 May 2012/Published online: 23 June 2012

(C) Springer Science+Business Media, LLC 2012

I read with great interest the article by Hong et al. [1]. They analyzed clinico-epidemiological characteristics of 52 patients with nodular gastritis (NG) and 2,527 controls. Gastric neoplasm was detected in a single patient in the NG group $(1.9 \%)$ and in five patients in the control group $(0.2 \%)$. In this study NG was associated with increased gastric neoplasia, including gastric adenoma and adenocarcinoma based on multivariate analysis (odds ratio $=10.52,95 \%$ CI $[1.20-92.0]$ ). The authors stated that the clinical implication of this finding was unclear because the range of the $95 \%$ CI was notably wide and a positive association between NG and gastric neoplasm could not be found in the subgroup analysis comparing the Helicobacter pylori (-) controls or H. pylori (+) controls [1].

The association between NG and gastric cancer have been previously suggested by various reports $[2,3]$. The major limitation of these series and the present study is the small size of the study populations. It is not possible to conclude a significant relationship between NG and gastric cancer with a few malignant cases in each series. This subject necessitates a large population-based follow-up study from an epidemiological perspective.

Another important point to note is that a plausible association between NG and gastric cancer should be supported by clinical and pathological evidence. We showed that the frequency of gastric ulcer (3.8 vs $7.1 \%$ ), atrophic gastritis (4.9 vs $12 \%$ ) and gastric polyp (2.2 vs

E. D. Onal $(\bowtie)$

Department of Endocrinology, Yıldırım Beyazit University Medical School Ataturk Teaching and Research Hospital, Ceyhun Atuf Kansu Cad Ehl-i Beyt Mah 1268. Sok 10/6, 06520

Bilkent, Balgat, Çankaya, Ankara, Turkey

e-mail: dredademir@gmail.com
$0.5 \%)$ was not significantly more frequent in patients with NG [4]. Only $8.1 \%$ of our patients had pangastritis and less than $5 \%$ had nodules in other parts of the stomach. For this reason, topographically, NG cannot be regarded as a type of pangastritis (so a precursor of atrophic gastritis) as some authors suggested [3]. There was no case of gastric cancer among our 185 patients with NG [4]. In another study we examined the pathological characteristics of the cases with NG [5]. Our results showed that there was no difference between the patients with NG and the control regarding the features as presence of severe dysplasia, inflammatory activity, intestinal metaplasia and lymphoid hyperplasia.

In conclusion NG cannot be accepted as a precancerous condition under the light of the pertinent literature.

\section{References}

1. Hong SN, Jo S, Jang JH, et al. Clinical characteristics and the expression profiles of inflammatory cytokines/cytokine regulatory factors in asymptomatic patients with nodular gastritis. Dig Dis Sci. 2012;57:1486-1495.

2. Miyamoto M, Haruma K, Yoshihara M, et al. Five cases of nodular gastritis and gastric cancer: a possible association between nodular gastritis and gastric cancer. Dig Liver Dis. 2002;34:819-820.

3. Miyamoto M, Haruma K, Yoshihara M, et al. Nodular gastritis in adults is caused by Helicobacter pylori infection. Dig Dis Sci. 2003;48:968-975.

4. Onal IK, Sokmensuer C, Onal ED, et al. Clinical and pathological features of nodular gastritis in adults. Turk J Med Sci. 2009;39: 719-723.

5. Sokmensuer C, Onal IK, Yeniova O, et al. What are the clinical implications of nodular gastritis? Clues from histopathology. Dig Dis Sci. 2009;54:2150-2154. 